\title{
Electrical Breakdown Properties of Oil-paper Insulation under Pulsating Voltage Influenced by Temperature
}

\author{
Lianwei Bao ${ }^{\dagger}$, Jian $\mathrm{Li}^{*}$, Jing Zhang* and Xudong $\mathrm{Li}^{*}$
}

\begin{abstract}
Insulation of valve-side windings in converter transformer withstands pulsating voltages, which will produce more serious insulation problems. In this paper, the electric breakdown experiments of oil-paper insulation specimens were executed at pulsating voltages and different temperatures. Experiment and analysis results showed that the breakdown voltage decreased with increasing temperature under pulsating voltage. The influence of temperature proves to be more significant once the temperature exceeds a limitation threshold. A fitting formula between breakdown voltage and the temperature was reported. Finally, in order to clearly understand the breakdown properties under pulsating voltage, the electric field distribution and space charge behavior under pulsating voltage at different temperature were discussed.
\end{abstract}

Keywords: Oil-paper insulation, Pulsating voltage, Ripple coefficient, Breakdown experiment, Temperature

\section{Introduction}

Converter transformer is a key point of hub device in high voltage direct current (HVDC) transmission system and operation of power system. Because oil-paper is the main insulation form in the converter transformer, its insulating properties directly affect the system's safe operation [1-2]. In the HVDC transmission system, converter valve will produce pulse voltage which has high amplitude and steep wave. This situation will make the valve-side windings of HVDC converter transformers withstand pulsating voltage stresses consisting of AC, DC, and strong harmonic components [3-5].

At present, oil impregnated paper insulation is widely used in converter transformers. However, there are still many problems relating to the presence of DC component. The report of CIGRE working group showed that the failure rate of the converter transformers was twice as much as the general transformers' [6]. According to investigation on the operating conditions of converter transformers [7], the insulation breakdown was found to be a common fault. In the insulation systems of converter transformers, DC voltage distribution significantly differs from that of AC voltage [8]. For this reason, in order to improve the reliability of converter transformers, it is essential to research the breakdown characteristics of oilpaper insulation under pulsating voltage.

Until then, a large number of researches about insulating

$\uparrow$ Corresponding Author: Electric Power Research Institute, CSG, Guangzhou, 510080, China. (baolw@csg.cn)

* State Key Laboratory of Power Transmission Equipment and System Security and New Technology, Chongqing University, China. (jianli@cqu.edu.cn)

Received: March 20, 2015; Accepted: December 9, 2015 properties of oil-paper insulation under AC, DC, or impulse voltage have been carried out. However, limited studies have been performed on insulating properties of the oilpaper insulation under pulsating voltage. Publications [910] presented the breakdown characteristics of oil-paper insulation under pulsating voltage. The effect of moisture content on breakdown characteristics of oil-paper insulation was also studied in reference [9]. Publication [11] presented the breakdown characteristics of XPLE under AC, DC and pulsating voltage. Reference [12] represented a brief introduction about the surface electric strength of processed pressboard under pulsating voltage. The electrical strength of oil-paper insulation under composite $\mathrm{AC}$ and lighting impulse voltages was researched in [13]. Publications [14-15] appointed out that the breakdown voltage of oil changes slightly as AC component increasing, but changes obviously under pulsating voltage. Also, temperature has a negative effect on oil-paper insulation life cycle by lowering electrical breakdown strength and thermal endurance [16]. Thus a better understanding of the influence of temperature on the breakdown properties of oil-paper insulation under pulsating voltage becomes especially important and practical.

This paper focuses on various contributing factors of electrical breakdown properties of oil-paper insulation under pulsating voltage. The effects of temperatures on the oil-paper insulating properties under pulsating voltage with different ripple coefficients were studied systematically. The experimental results were discussed in this paper, relationships between ripple coefficients and breakdown voltage were established at different temperatures, and a fitting formula between breakdown voltage and the temperature was reported. 


\section{Experiments}

\subsection{Experimental Setup}

Fig. 1 shows the setup of multiple factors test under pulsating voltage in the laboratory. The $\mathrm{AC}$ voltage was supplied by a corona free test transformer, and the DC voltage was created by half wave rectifier circuit. The pulsating voltages, combined with $\mathrm{AC}$ and DC voltages, were applied on the oil-paper insulation specimens. The breakdown voltages were measured by oscilloscope via high voltage probe. Aging chamber was used to adjust the testing temperature of the sample, so as to research temperature's influence on the breakdown properties of oilpaper insulation. Fig. 2 shows the final voltage waveform added on the test sample. Ripple coefficient $(r)$ is defined as the ratio of peak value of $\mathrm{AC}$ component to $\mathrm{DC}$ component level [9]:

$$
r=V_{\mathrm{AC}} / V_{\mathrm{DC}}
$$

Test electrode system was designed in accordance with publication [17], as shown in Fig. 3. The electrode system and oil-paper samples were completely immersed in transformer oil during experiments. The Kraft pulp insulation paper and Karamay 25\# transformer oil were used in this work. The diameter and thickness of oil-paper insulation specimens were $80 \mathrm{~mm}$ and $0.2 \mathrm{~mm}$ respectively. The transformer oil was used for oil impregnation of insulation paper. Before the test, the insulating paper was

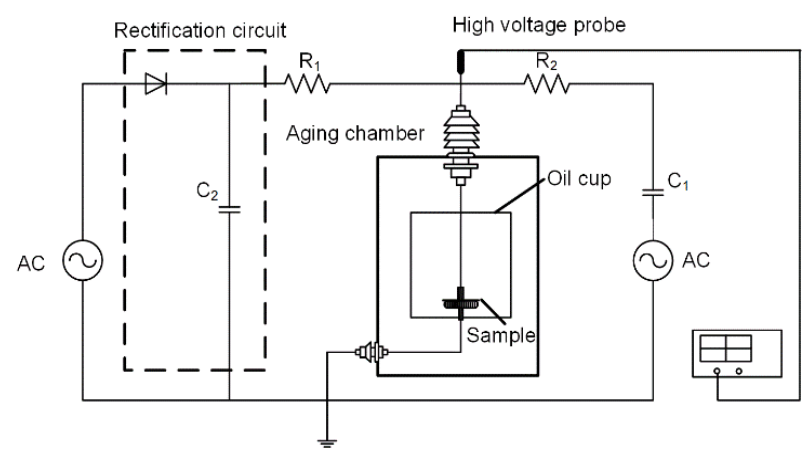

Fig. 1. Setup of multiple coefficients test under pulsating voltages

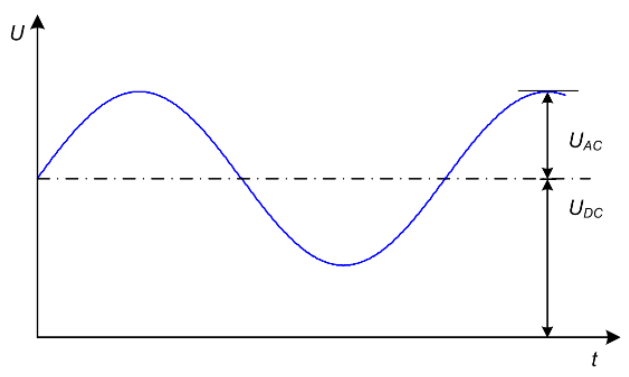

Fig. 2. The waveform of pulsating voltage

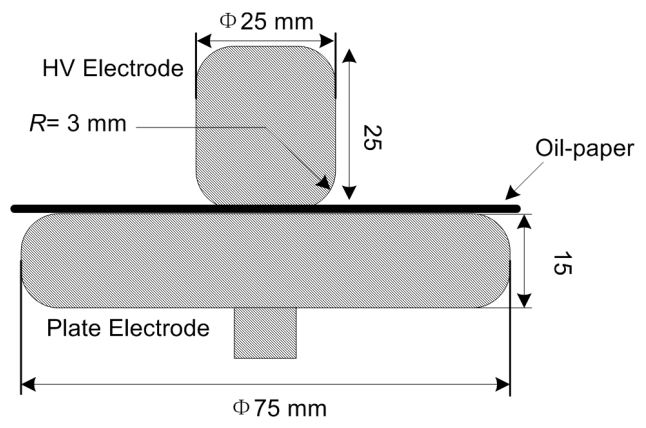

Fig. 3. Test electrode system

dried in a drying oven at $90{ }^{\circ} \mathrm{C}$ for 24 hours. The transformer oil was dried for 24 hours in the vacuum oil tank when the temperature in it is $45^{\circ} \mathrm{C}$ and the degree is $200 \mathrm{~Pa}$. Afterwards, the dried insulation paper was impregnated in transformer oil in vacuum of $200 \mathrm{~Pa}$ at $45^{\circ} \mathrm{C}$ for 72 hours.

\subsection{Experimental Method}

Based on relevant standards [17], short-term boost method was adopted to carry out the breakdown experiments of oilpaper insulation under pulsating voltage. To make sure most of the breakdowns occurring in $10 \mathrm{~s} \sim 20 \mathrm{~s}$, the rising rate of peak values of $\mathrm{AC}$ voltage was chose to be $1 \mathrm{kV} / \mathrm{s}$ and the DC voltage to be $2 \mathrm{kV} / \mathrm{s}$.

Five oil-paper insulation specimens were prepared for tests and the median one was considered to be the breakdown voltage of these specimens. If the maximum difference between the median and each breakdown voltage was greater than 15 percent of the median, five more oil-paper samples were used to measure their breakdown voltages. The median breakdown voltage of the total of specimens was considered as the breakdown voltage.

\section{Tests at Different Pulse Coefficients}

For the inverter, the rated voltage $U_{\mathrm{dr}}=1.175 U_{\mathrm{AC}}$, in which, $U_{\mathrm{AC}}$ is the phase-to-phase voltage. The DC voltage in valve-side winding is $(p-0.5) U_{\mathrm{dr}}$, and $p$ is the number of bridges. The AC voltage in valve-side winding is $U_{\mathrm{AC}} / \sqrt{3}$ [18]. Taking the converter transformer used in $\pm 800 \mathrm{kV}$ HVDC power transmission project as an example, the values of $p$ equal to $1,2,3$ and 4 . The turn-to-ground insulation of valve-side windings is subjected to a pulsating voltage with a ripple coefficient $(r)$ equaling to 1 , $1 / 3,1 / 5$ and $1 / 7$, respectively. At pulsating voltages with different ripple coefficients, the insulation properties show corresponding distinctions to each other, and this should not be ignored in the insulation examination for different parts of converter transformer.

In this work, the breakdown voltages of oil-paper 
samples were first tested to investigate the influence of ripple coefficient at room temperature. Two methods were adopted during the experiments. First, the AC component was raised to a preset value, and then the DC component was raised at a constant rate until the insulation breakdown happened. In the same way, the DC component was to a preset value, and then the AC component was raised. The breakdown values were recorded after the breakdown occurred. During experiments, the value of ripple coefficient was controlled to be from 0.05 to 10 .

Fig. 4 shows the $95 \%$ confidence interval of breakdown voltages, AC and DC components with increasing of ripple coefficient at pre-applied AC voltage. The tests data have a certain degree of dispersion as shown in the figure. The experimental results show that breakdown voltage of oilpaper insulation reaches highest under individual DC voltages. As increase of ripple coefficient, the breakdown voltage decreases in a nonlinear curve. The least breakdown voltage value was obtained under individual AC voltage.

Fig. 5 shows the $95 \%$ confidence interval of breakdown voltages, $\mathrm{AC}$ and $\mathrm{DC}$ components as ripple coefficients increasing at the pre-stressed $\mathrm{DC}$ voltage condition. The same law as the pre-stressed AC voltage test was obtained. However, the scatter in the pre-stressed DC voltage tests was smaller than that of the pre-applied AC voltage.

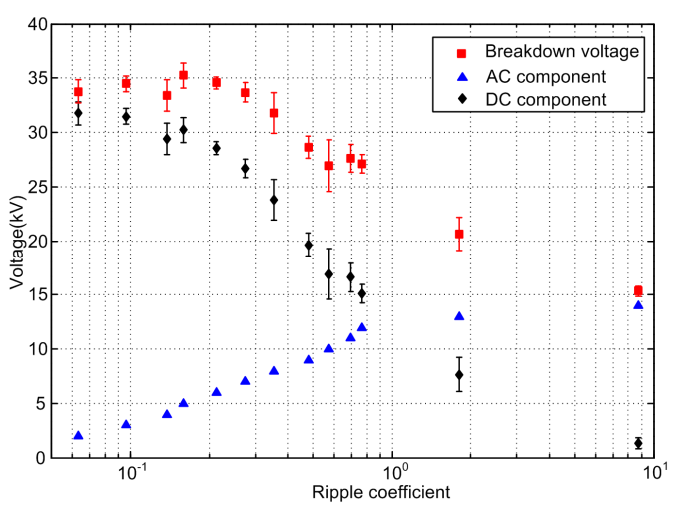

Fig. 4. Plot of $95 \%$ confidence interval of breakdown voltage (pre-AC voltage)

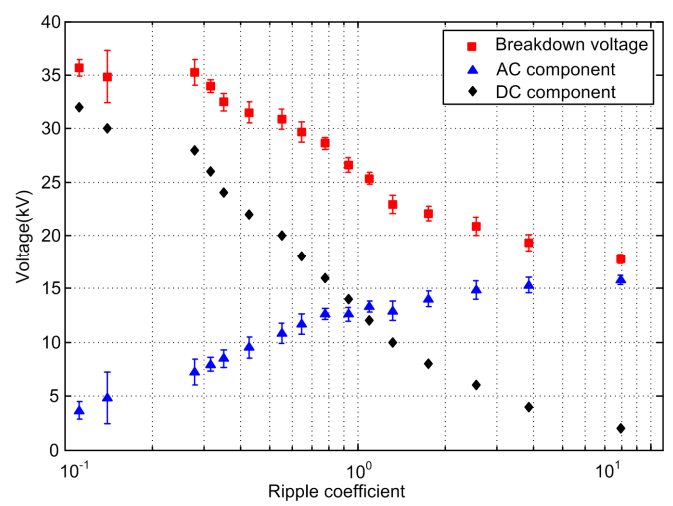

Fig. 5. Plot of $95 \%$ confidence interval of breakdown voltage (pre-DC voltage)
There is a relationship among the breakdown voltage under pulsating voltage $V_{B}$, AC component $V_{A C}, \mathrm{DC}$ component $V_{D C}$ and ripple coefficient $r$, as follows [9, 11]:

$$
\left\{\begin{array}{l}
V_{B}=V_{d c}+V_{a c} \\
V_{D C}=\frac{2}{\pi} \cdot A \cdot \operatorname{arccot}(r / \alpha) \\
V_{A C}=\frac{2}{\pi} \cdot B \cdot \arctan (r / \beta)
\end{array}\right.
$$

where, $V_{B}$ is breakdown voltage, $V_{D C}$ is DC component, and $V_{A C}$ is AC component. $A$ is breakdown voltage under individual DC voltage, $B$ is breakdown voltage under individual AC voltage, and $\alpha$ is the value of $r$ when the DC component is $0.5 A, \beta$ is the value of $r$ when the $\mathrm{AC}$ component is $0.5 B$. The parameters $\alpha$ and $\beta$ can be calculated out by Newton's method, therefore only values of $A$ and $B$ are required.

Using the breakdown voltage under individual $\mathrm{AC}$ and individual DC voltages, $16.6 \mathrm{kV}$ and $36.2 \mathrm{kV}$ respectively, $\alpha=0.6509$ and $\beta=0.3230$ can be obtained by Newton's method. The data of breakdown voltages of oil-paper insulation was fitted by Equations (2). Table 1 contains the fitting parameters and calculated values of parameters in equations (2) from different pre-stressed voltage type experiments.

The fitting curves and calculated curve of breakdown voltages were shown in Fig. 6. The results indicated that Eq. (2) fitted well to test data. There was a certain deviation between the experimental results and the theoretical calculation. The breakdown voltage of pre-

Table 1. Fitting parameters and calculated value of parameters

\begin{tabular}{c|c|c|c|c}
\hline Experiments & $A$ & $B$ & $\alpha$ & $\beta$ \\
\hline Calculated value & 36.20 & 16.60 & 0.6509 & 0.3230 \\
\hline Pre-AC & 35.33 & 15.97 & 0.5819 & 0.2886 \\
\hline Pre-DC & 35.71 & 16.12 & 0.6531 & 0.3120 \\
\hline
\end{tabular}

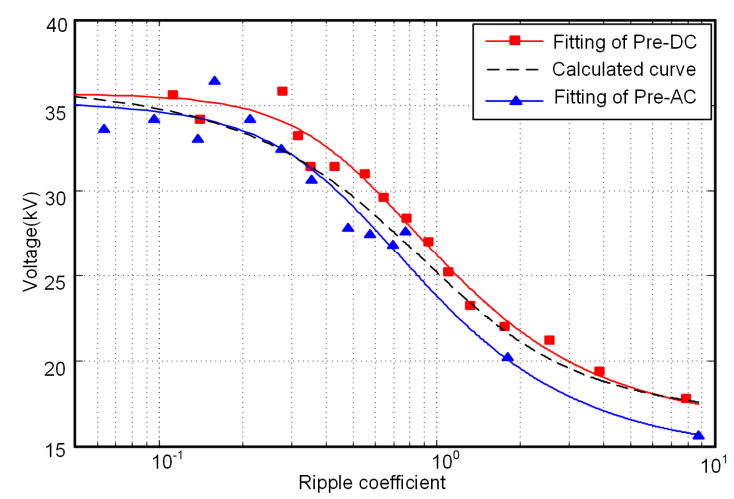

Fig. 6. The fitting curves and calculated curve of breakdown voltage 
stressed DC component was slightly higher than that of the pre-stressed AC component. The biggest difference between pre-stressed DC and pre-stressed AC appears in $r=0.8$. It is believed that the space charge accumulation plays an important role in this phenomenon. However, it is practicable to estimate the oil-paper insulation properties under pulsating voltage with different ripple coefficient by equations (2) in engineering application.

\section{Tests at Different Temperatures}

Previous research results demonstrated that temperature has an obvious effect on the insulating property of oilpaper insulation [14-15, 19]. The oil-paper insulation breakdown tests at different temperatures were carried out in laboratory conditions. The temperatures were designed to be $70^{\circ} \mathrm{C}, 90^{\circ} \mathrm{C}, 110^{\circ} \mathrm{C}$, and $130^{\circ} \mathrm{C}$ separately.

\subsection{Test Results}

During the different temperatures tests, Eq. (2) was used to fit the test data. Fitting curves were shown in Figs. 7-9. Table 2 and 3 showed the fitting parameters and calculated value of parameters in equations (2) at different temperatures. The result revealed that the parameters $\alpha$ and $\beta$ have some regularity as the temperature raised. Further study is necessary to clarify the relationship between the parameters $\alpha, \beta$ and temperatures.

Through comparison between the data in Table 2 and 3 , the experiment data are similar to the calculated values by equations (2). Furthermore, Table 4 shows the goodness of fit of parameters $A, \alpha$ and $B, \beta$ in equations (2), which means that the equations (2) have a high forecasting

Table 2. Fitting parameters of formula (2)

\begin{tabular}{c|c|c|c|c}
\hline Temperature & $A$ & $B$ & $\alpha$ & $\beta$ \\
\hline $70^{\circ} \mathrm{C}$ & 27.3 & 13.8 & 0.7816 & 0.3161 \\
\hline $90^{\circ} \mathrm{C}$ & 26.7 & 14.2 & 0.8046 & 0.3292 \\
\hline $110^{\circ} \mathrm{C}$ & 20.8 & 14.4 & 1.0690 & 0.4314 \\
\hline $130^{\circ} \mathrm{C}$ & 9.4 & 10.1 & 1.5500 & 0.7520 \\
\hline
\end{tabular}

Table 3. Calculated value of parameters of formula (2)

\begin{tabular}{c|c|c|c|c}
\hline Temperature & $A$ & $B$ & $\alpha$ & $\beta$ \\
\hline $70^{\circ} \mathrm{C}$ & 28.2 & 13.0 & 0.6542 & 0.3248 \\
\hline $90^{\circ} \mathrm{C}$ & 23.8 & 14.0 & 0.8267 & 0.4185 \\
\hline $110^{\circ} \mathrm{C}$ & 18.8 & 14.2 & 1.0397 & 0.5334 \\
\hline $130^{\circ} \mathrm{C}$ & 9.4 & 9.0 & 1.3330 & 0.6879 \\
\hline
\end{tabular}

Table 4. The goodness of fit of parameters

\begin{tabular}{c|c|c}
\hline Temperature & Parameters $A, \alpha$ & Parameters $B, \beta$ \\
\hline $70^{\circ} \mathrm{C}$ & 0.9965 & 0.9530 \\
\hline $90^{\circ} \mathrm{C}$ & 0.9815 & 0.8691 \\
\hline $110^{\circ} \mathrm{C}$ & 0.9878 & 0.9405 \\
\hline $130^{\circ} \mathrm{C}$ & 0.9889 & 0.9970 \\
\hline
\end{tabular}

accuracy at different temperatures.

Fig. 7 shows the breakdown voltage varies with ripple coefficient at different temperatures. The test results show that the smaller the ripple coefficient is, the more obvious the temperature's effect on the breakdown voltage of the oil-paper becomes, meaning that $\mathrm{DC}$ voltage component is especially sensitive to temperature. On the contrary, the temperature's effect on the breakdown voltage of oil-paper insulation under pulsating voltage $(r>1)$ is not obvious

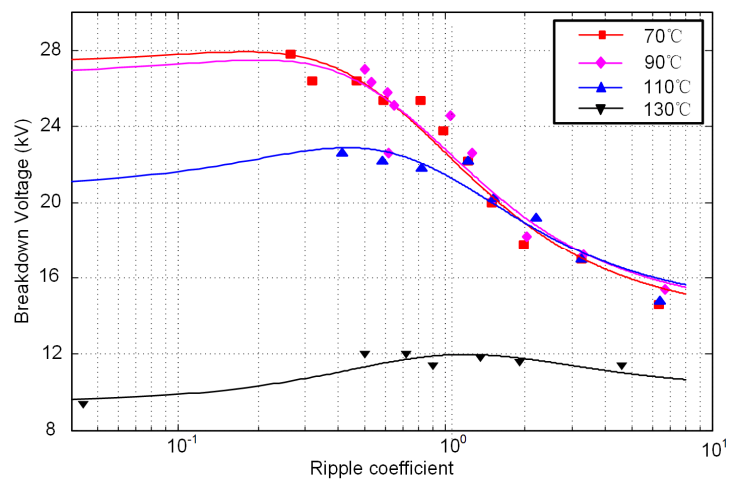

Fig. 7. The relation of breakdown voltage to $r$ at different temperature.

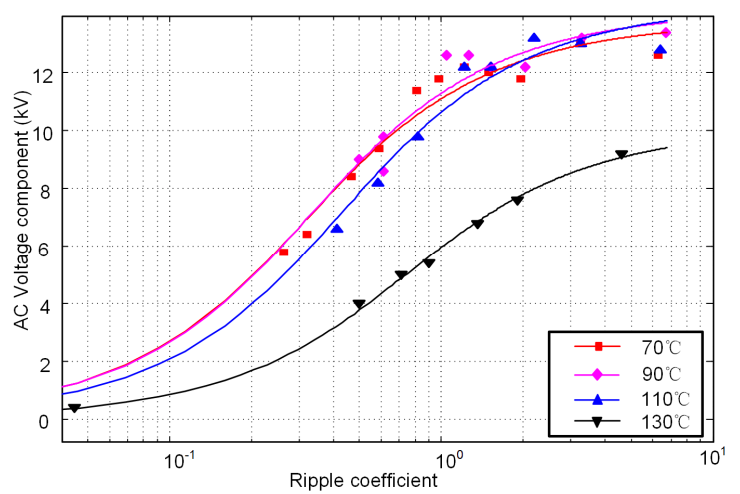

Fig. 8. The relationship of $\mathrm{AC}$ voltage component to $r$ at different temperatures.

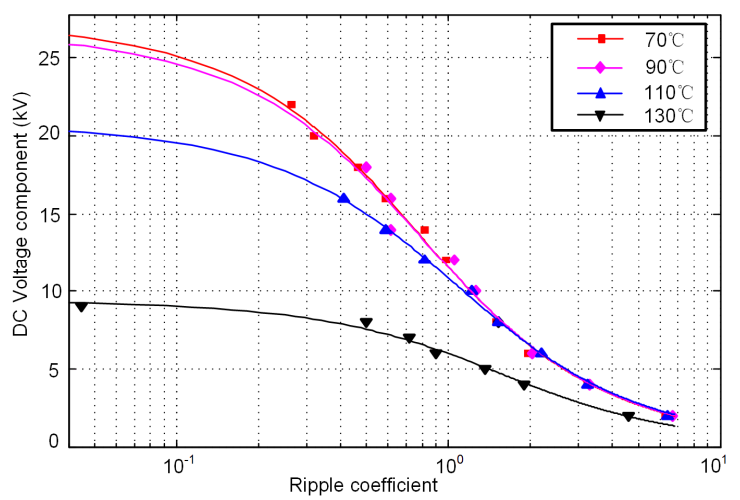

Fig. 9. The relationship of DC voltage component to $r$ at different temperatures. 
when temperature is below $110^{\circ} \mathrm{C}$. At $130^{\circ} \mathrm{C}$, the insulating properties of the oil-paper insulation decrease severely, which will lead to the breakdown voltage under pulsating voltage decreases obviously, especially under the pulsating voltage $(r<0.3)$.

Fig. 8 and 9 show the variation law of how AC and DC components change as the ripple coefficient changes at different temperatures. Fitting curves in figures explain that AC voltage component changes slightly when the temperature is between $70 \sim 110^{\circ} \mathrm{C}$. However, it decreases sharply when the temperature is above $110^{\circ} \mathrm{C}$. On the other hand, the DC voltage component changes slightly between $70 \sim 90^{\circ} \mathrm{C}$ and decreases obviously when the temperature is above $90^{\circ} \mathrm{C}$. It can be concluded that the reduction in ability of oil-paper insulation to withstand DC voltage resulted in the decrease of the breakdown voltage at $90 \sim 110^{\circ} \mathrm{C}$. Therefore, it will help to improve transformer operational reliability by keeping the temperature of transformer oil below $90^{\circ} \mathrm{C}$.

\subsection{Analysis of Test Results}

The relationship between the breakdown voltage of oilpaper insulation and temperature under pulsating voltage was studied. Pulsating voltages with ripple coefficients equal to 0 (individual DC voltage), $0.1,0.2,0.5,1,2,5$ and $\infty$ (individual AC voltage) were selected.

By analyzing the relationship of breakdown voltage to temperature for selected ripple coefficients, Eq. (3) was used to fit the data, as shown in Fig. 10.

Table 5. The fitting parameters of the fitting curve

\begin{tabular}{c|c|c|c}
\hline$p$ & $a$ & $b$ & R-square \\
\hline 0 & $-3.7 \mathrm{e}-6$ & 3.202 & 0.9974 \\
\hline 0.1 & $-1.3 \mathrm{e}-12$ & 6.223 & 0.9970 \\
\hline 0.2 & $-1.4 \mathrm{e}-13$ & 6.673 & 0.9977 \\
\hline 0.5 & $-9.6 \mathrm{e}-15$ & 7.194 & 0.9955 \\
\hline 1 & $-7.0 \mathrm{e}-15$ & 7.194 & 0.9706 \\
\hline 2 & $-4.8 \mathrm{e}-15$ & 7.194 & 0.9287 \\
\hline 5 & $-3.4 \mathrm{e}-15$ & 7.194 & 0.8911 \\
\hline$\infty$ & $-2.9 \mathrm{e}-15$ & 7.194 & 0.7955
\end{tabular}

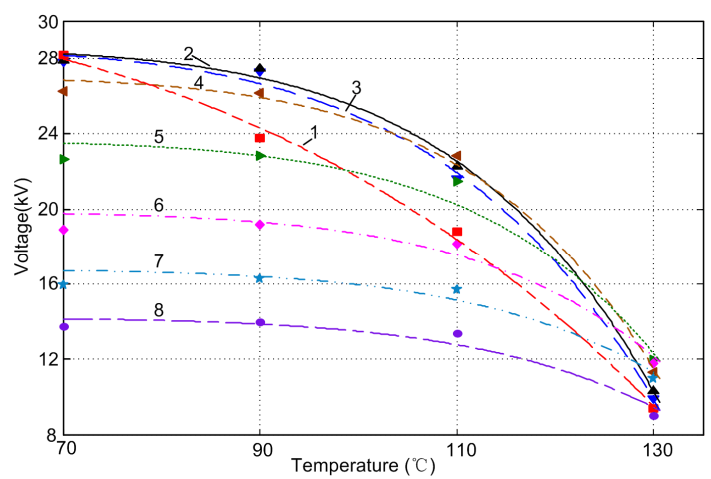

1. $r=0 ; 2 . r=0.1 ; 3 . r=0.2 ; 4 . r=0.5 ; 5 . r=1 ; 6 . r=2 ; 7 . r=5 ; 8 . r=\infty$.

Fig. 10. The fitting curves of the breakdown voltage variation with temperature

$$
U(T)=a \cdot T^{b}+U_{0}
$$

where, $T$ is the temperature, $U_{0}$ is the breakdown voltage at $70^{\circ} \mathrm{C}$, and $a, b$ are parameters related to ripple coefficients.

Observing the curves changing rule in Fig. 10, the smaller ripple coefficient is, the faster the breakdown voltage of the oil-paper insulation decreases. Table 5 is the fitting parameters of the fitting curves. According to the data in Table 5, the following information may be gained: when the pulse coefficient is small, parameter $a$ turns to vary greatly; when $r>0.5$, it maintains in the same order of magnitude. Parameters $b$ has a similar rule to $a$, the value of $b$ is stable at 7.194, when $r>0.5$. The result shows that the parameters $a, b$ have a greater correlation with ripple coefficients.

The curves and data show that the Eq. (3) is suitable for describing the relationship between temperature and breakdown voltage of oil-paper insulation under pulsating voltages.

\section{Discussion}

\subsection{Electric Field Distribution at Pulsating voltage}

The insulation paper contians a large number of bubbles, after the progress of oil paper impregnation, these bubbles in insulation paper will be filled with insulation oil. The model of oil-paper insulation is represented in in Fig. 11 (a), which can be simplified as a double composite dielectric model, as shown in Fig. 11 (b). The $\varepsilon_{1}, \gamma_{1}, d_{1}$ and $\varepsilon_{2}, \gamma_{2}, d_{2}$ are the permittivity, conductivity and thichness of oil layer and paper layer, respectively.

At AC voltage, the electric field distribution in oilpaper insulation is mainly determined by permittivity, while under pulsating voltage, it depends on not only the permittivity but also conductivity. Using the superposition principle of electric field, the electric field strength in the insulating paper and oil gap $E_{\text {Paper }}$ and $E_{\text {Oil }}$ can be expressed as follows:

$$
E_{\text {Paper }}=U_{A C} \cdot \frac{\varepsilon_{2}}{\varepsilon_{2} d_{1}+\varepsilon_{1} d_{2}}+U_{D C} \cdot \frac{\gamma_{2}}{\gamma_{2} d_{1}+\gamma_{1} d_{2}}
$$

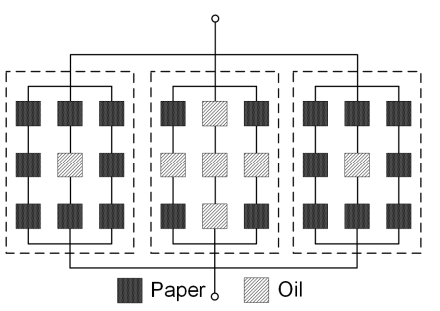

(a)

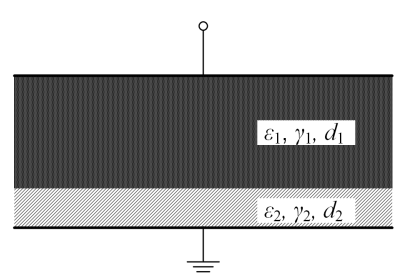

(b)
Fig. 11. Equivalent circuit of oil-paper insulation and the double composite dielectric model 


$$
E_{O i l}=U_{A C} \cdot \frac{\varepsilon_{1}}{\varepsilon_{1} d_{2}+\varepsilon_{2} d_{1}}+U_{D C} \cdot \frac{\gamma_{1}}{\gamma_{2} d_{1}+\gamma_{1} d_{2}}
$$

The electric field distributions of the double composite dielectric model were calculated under different conditions. The peak value of applied voltages has been set to $30 \mathrm{kV}$. Fig. 12 shows the electric field distributions under different voltage types at $30^{\circ} \mathrm{C}$. As shown in Fig. 12, the voltage applied on the oil-paper insulation was mainly withstanded by the insulation oil under AC voltage. As the DC component of pulsating voltage increased, the electric field in the insulation oil decreased while it increased in the insulation paper. Under DC voltage the applied voltage was mainly withstanded by insulation paper.

From above disscusion, a conclusion can be reached, that the breakdown strength of oil-paper insulation mainly depends on the breakdown strength of insulation oil at AC voltages. Instead, the breakdown strength mainly depend on the breakdown strength of insulation paper at pulsating DC and individual DC votages. Because the electrical breakdown field stress in insulation paper is much larger than that in insulation oil, the breakdown strength of oilpaper insulation at pulsating $\mathrm{DC}$ and individual DC voltages are much larger than at individual $\mathrm{AC}$ voltages.

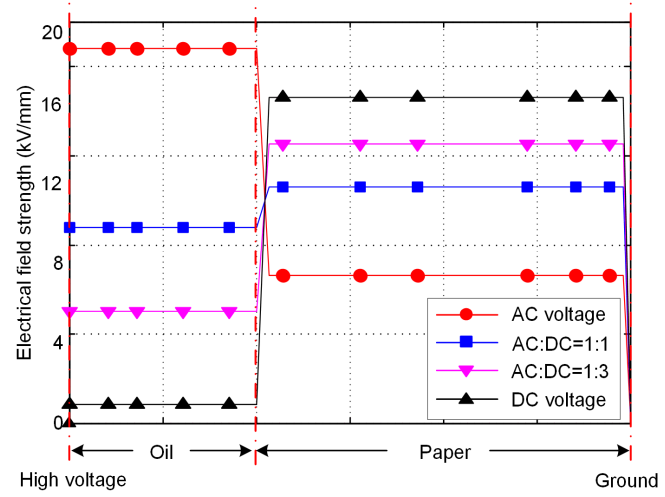

Fig. 12. Electric distribution in the double composite dielectric model at different voltage types

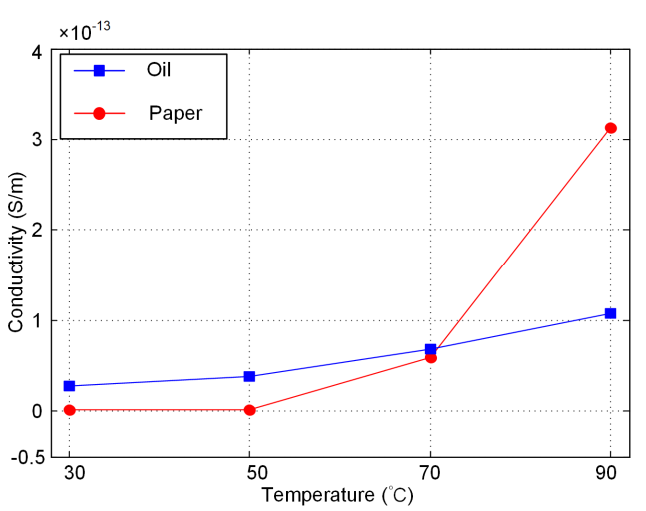

Fig.13. Conductivity variations of the oil and the paper at different temperatures
The temperature has a significant effect on the conductivity, as shown in Fig. 13. It can be concluded that, the conductivity variations of paper is an important reason which reduces the breakdown voltage under pulsating voltage at greater temperature.

Fig. 14 and 15 show the calculated reasults of electric distribution in the double composite dielectric model at different temperatures. It is noticed that with increase in temperature, the electric distribution at $\mathrm{AC}$ voltage basically kept unchanged. However, the change of electric distribution at pulsating voltage is evident as the temperature rising gradually from low to high. The electric field strength increased in insulation oil and decreased in insulation paper with rising temperature. When the temperature reaches $90^{\circ} \mathrm{C}$, the electric field distribution in oil-paper insulation under pulsating voltage is similar with that under individual AC voltage, which explains the significant drop in breakdown voltages under pulasting DC voltage at higher temperature.

\subsection{Space Charge Behavior in Oil-Paper Insulation}

The oil-paper insulation is a typical composite structure. The space charge will accumulation in the oil-paper

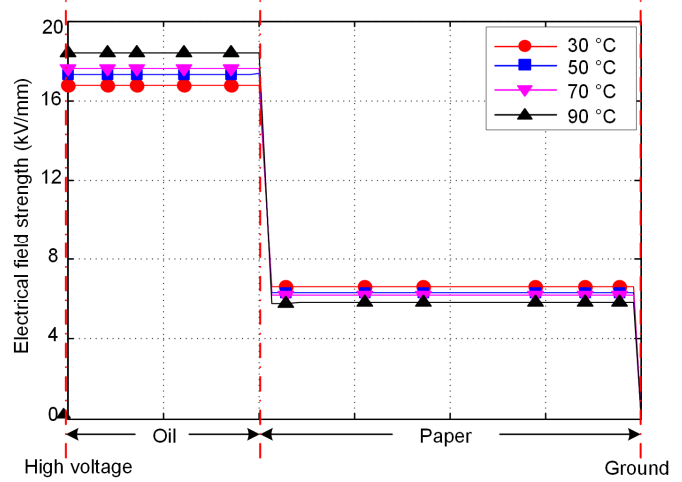

Fig. 14. Electric distribution in the double composite dielectric model under AC voltage

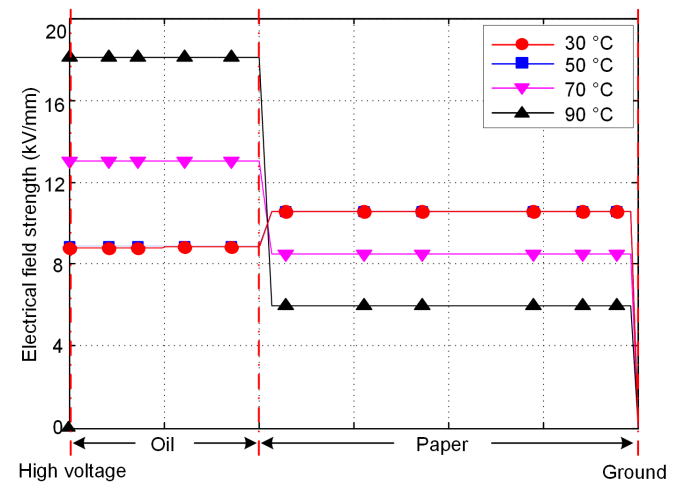

Fig. 15. Electric distribution in the double composite dielectric model at pulsating voltage with $r$ equal to 1 


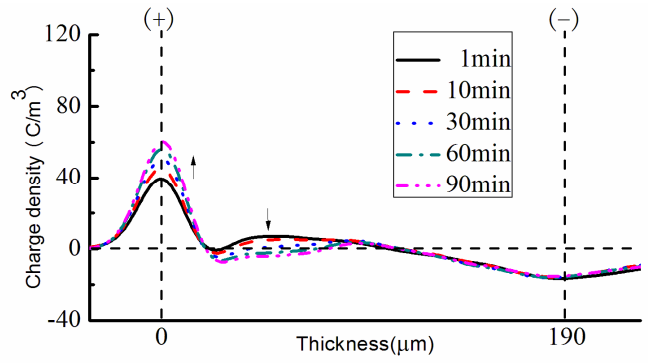

(a) $70^{\circ} \mathrm{C}$

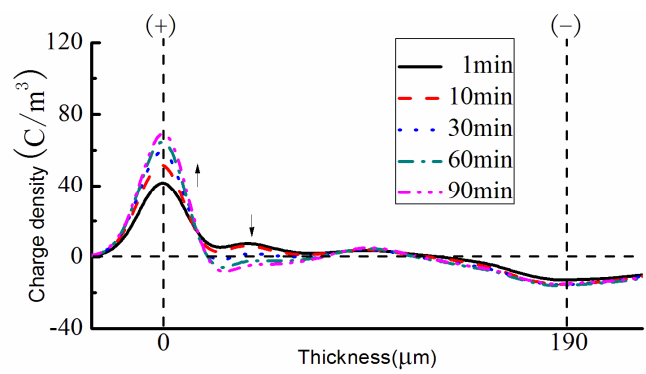

(b) $90^{\circ} \mathrm{C}$

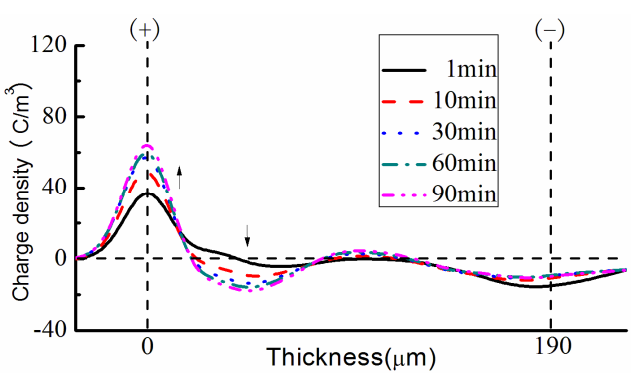

(c) $110^{\circ} \mathrm{C}$

Fig.16. Space charge dynamics for oil-paper at $30 \mathrm{kV} / \mathrm{mm}$ and different temperatures

insulation structure under DC voltage. The space charge in oil-paper insulation would induce an opposing electric field and it weakened the electric stress applied on the insulation. This mainly incarnates that the breakdown voltage under DC voltages and pulsating voltages is higher, and it also caused the breakdown voltage under pre-DC voltage higher than that under pre-AC voltage.

Space charges injected into the oil-paper insulation samples will result in the electric field distortion, influence the charge decay. When the test temperature increases, the injected charges have more energy and the charge moves faster [20]. At the same voltage, the max electrical field after volts-off increases with the increase of temperature. This also leads to the drop of breakdown voltage at higher test temperature.

Fig. 16 shows the aging temperature influence on charge density in oil-paper insulation. Those insulation samples were aged for 6 hours at $70^{\circ} \mathrm{C}, 90^{\circ} \mathrm{C}$ and $110^{\circ} \mathrm{C}$. Charge density and the amount of space charge increase with increasing temperature. Moreover, temperature also has a significant influence on space charge distribution, which may result in an electric field distortion.

\section{Conclusions}

This paper presents research on the breakdown properties of oil-paper insulation at pulsating voltage with different ripple coefficients. The influence of temperature on the breakdown properties of oil-paper insulation was studied. The changing rules of breakdown voltages, AC component and DC component at different temperatures and pulsating voltages were obtained. The results of above work and analysis are concluded as follows.

1) The different types of pre-stressed voltages have certain effect on the breakdown voltage of the oil-paper insulation. The breakdown voltage of pre-stressed DC voltage turns out to be larger and with smaller scatter than that of the pre-stressed AC-voltage.

2) The effect of temperature becomes greater at the pulsating voltage with small ripple coefficients. The test result shows that, the effect of temperature on the DC component is especially obvious, but slight on AC voltage component.

3) The relationship between the breakdown voltage of oil-paper insulation at pulsating voltage and different temperatures could be described by this formula: $U(T)=$ $a \cdot T^{b}+U$.

4) Temperature has a significant influence on space charge distribution, which may result in the electric field distortion and the drop of breakdown voltage.

\section{Acknowledgements}

The authors acknowledge the funding of the 973 Program (2012CB215205). The National Natural Science Foundations of China $(51177180,51321063)$ are also appreciated.

\section{References}

[1] G. Bhuvaneswari, B. C. Mahanta, "Analysis of Converter Transformer Failurein HVDC Systems and Possible Solutions", IEEE Trans. Power Del., Vol. 24, pp. 814-821, 2009.

[2] Yong Li, Longfu Luo and Christian Rehtanz, "Study on Characteristic Parameters of a New Converter Transformer for HVDC Systems", IEEE Trans. Power Del., Vol. 24, pp. 2125-2131, 2012.

[3] L.Yang, S. M. Gubanski, "Dielectric Properties of Transformer Oils for HVDC Applications," IEEE 
Trans. Dielectr. Electr. Insul., Vol. 19, pp. 1926-1933, 2012.

[4] Astrom, Lars Weimers, Victor Lescale and Gunnar Asplund, "Power transmission with HVDC at voltages above 600kV", Urban 2005 IEEE/PES Transmission and Distribution Conference \& Exibition: Asia and Pacific, Dalian, China, pp. 1-7, 2005.

[5] R. Sarathi and G. Koperundevi, "UHF technique for identification of partial discharge in a composite insulation under AC and DC voltages", IEEE Trans. Dielectr. Electr. Insul. Vol. 15, pp. 1724-1730, Dec. 2008.

[6] "HVDC Converter Stations for Voltages Above \pm 600 kV", Report of Cigre Working Group 14.32, 2002.

[7] D. H. Grant and W. McDermid, "Assessment of Thermal Aging of HVDC Converter Transformer Insulation", IEEE Int'l Sympos. Electr. Insul., 19-22 Sep. 2004

[8] Y. Ebisawa et al. "DC Creepage Breakdown Characteristics of Oil-immersed Insulation", IEEE Trans. Power Del., Vol. 16, pp. 1686-1692, No. 6; 2009.

[9] H. Nowaczyk, S. Grzybowski, E. Kuffel, "Electrical breakdown strength of paper-oil insulation under pulsating voltages", IEEE Trans. Electr. Insul., Vol. El-22, pp. 249-253, 1987.

[10] Lida Jauregui-Rivera, Xiaolin Mao, and Daniel J. Tylavsky, "Improving reliability assessment of transformer thermal top-oil model parameters estimated from measured data," IEEE Trans. Power Del., Vol. 24, pp. 169-176, 2009.

[11] S. Grzybowski, J. Fan, "Electrical breakdown characteristics of the XLPE cables under AC, DC and pulsating voltages", IEEE Conf. Properties and Applications of Dielectr. Materials, Seoul, Korea, pp. 389-393, 1997.

[12] M. R. Raghuveer, Z. Kolaczkowski, J. Weifang, E. Kuffel, "Surface electric strength of processed pressboard under composite AC and DC and conventional stresses", IEEE Trans. Electr. Insul., Vol. 25, pp. 341350,1990 .

[13] F. Mosinski, J. Wodzinski, "Electrical strength of paper-oil insulation subjected to composite voltages", IEEE Trans. Dielectr.Electr. Insul., Vol. 1, pp.615623,1994.

[14] Sajan, J. S., Dwarakanath, K., Moorching, S. N., "Comparative evaluation of dielectric strength of paper-oil insulation under ac, dc, combined, composite ac/dc and impulse voltages", IEEE Conf. Electr. Insul. Dielectr. Phenomena, Quebec, Canada, pp.236-239, vol.1, 1998.

[15] Lianwei Bao, Jian Li, Jinzhuang Lv, Zhiman He. "Electrical breakdown characteristics of oil-paper insulation under pulsating voltage", International Conf. High Voltage Engineering and Application, Shanghai, China, September17-20, 2012.
[16] Y. Wang, X. Wang, Q. Cheng. etc., "Breakdown Characteristics of Converter Transformer Insulation under Composite AC and DC Voltage", IEEE Conf. Properties and Applications of Dielectr. Materials, Harbin, China, pp.634-637, 2009.

[17] IEC 62539:2007/ IEEE Std 930-2004, IEEE Guide for the Statistical Analysis of Electrical Insulation Breakdown Voltage Data, 2007.

[18] Kennedy W N, Crichton C C, Cillies D A, et al. "Recommended dielectric tests and test procedures for converter transformers and smoothing reactors", IEEE Trans. Power Del., Vol. 1, No. 3, pp. 161-166, 1986.

[19] J. Alan, C. Forrest, and B. Allard, "Thermal problems caused by harmonic frequency leakage fluxes in three-phase three-winding converter transformers," IEEE Trans. Power Del., Vol. 19, No. 1, pp. 208-213, 2004.

[20] Chao Tang, G. Chen, M. Fu, Ruijin Liao, "Space charge behavior in multi-layer oil-paper insulation under different DC voltages and temperatures", IEEE Trans. Dielectr. Electr. Insul., Vol. 17, pp. 778-788, 2010.

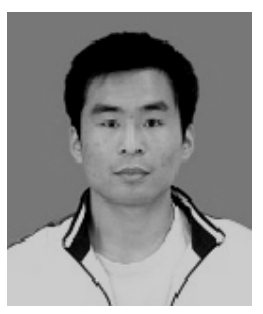

Lianwei Bao received the Bachelor and $\mathrm{Ph}$. D degree in electrical engineering in 2010 and 2016, from Southwest Jiaotong University and Chongqing University, Chongqing, China. He is currently working as a researcher in Electric Power Research Institute, CSG, Guangzhou, China. His major research interests include online condition monitoring and fault diagnosis of high voltage equipment, aging properties of insulation materials, and probabilistic analysis to insulation failure data.

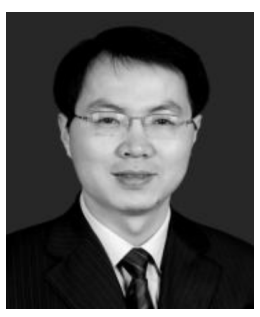

Jian Li received the M.S. and Ph.D degree in electrical engineering in 1997 and 2001, from Chongqing University, Chongqing, China. He is currently a professor and the Associate Dean of School of Electrical Engineering at Chongqing University. His major research interests include online condition monitoring and fault diagnosis of HV equipment, environment-friendly insulation materials and nano dielectrics. He is an author and co-author of more than 80 journal papers and 60 papers published in proceedings of international conferences. 


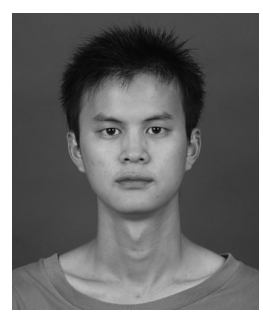

Jing Zhang received the Bachelor degree in electrical engineering and automation in 2012, from China University of Mining and Technology, Xuzhou, China. He is currently a Ph.D. candidate at Chongqing University. His major research interests include online condition monitoring and fault diagnosis of high voltage equipment, aging properties and diagnosis of insulation materials and structures in transformers.

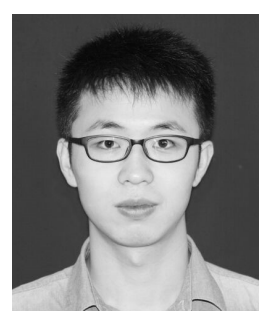

Xudong Li received the Bachelor degree in electrical engineering in 2013, from Chongqing University, Chongqing, China. He is currently a Ph.D. degree candidate in the electrical engineering college of Chongqing University, Chongqing, China, His major research interests include partial discharge, new sensors for condition monitoring and insulation fault diagnosis of high voltage equipment. 